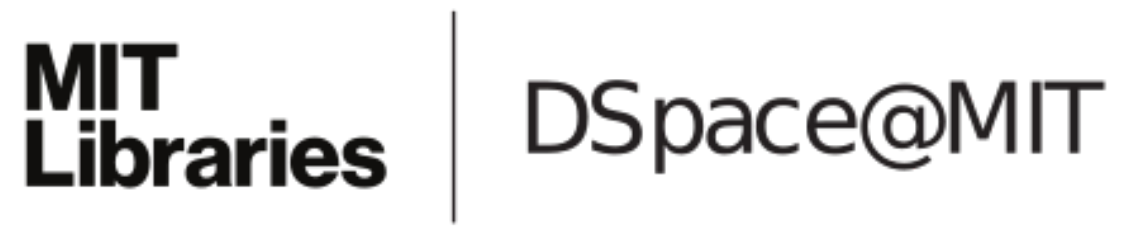

\author{
MIT Open Access Articles
}

Quantum chemical approaches to [NiFe] hydrogenase

The MIT Faculty has made this article openly available. Please share how this access benefits you. Your story matters.

Citation: Vaissier, Valerie and Troy Van Voorhis. "Quantum Chemical Approaches to [NiFe] Hydrogenase." Essays In Biochemistry 61, 2 (May 2017): 293-303 ( 2017 The Author(s)

As Published: https://doi.org/10.1042/EBC20160079

Publisher: Portland Press

Persistent URL: http://hdl.handle.net/1721.1/115113

Version: Author's final manuscript: final author's manuscript post peer review, without publisher's formatting or copy editing

Terms of use: Creative Commons Attribution-Noncommercial-Share Alike 


\title{
Quantum Chemical Approaches to [NiFe] Hydrogenase
}

\author{
Valerie Vaissier and Troy Van Voorhis* \\ Department of Chemistry \\ Massachusetts Institute of Technology \\ 77 Massachusetts Ave. \\ Cambridge, MA 02139 USA
}

\begin{abstract}
The mechanism by which [NiFe] hydrogenase catalyzes the oxidation of molecular hydrogen is a significant yet challenging topic in bioinorganic chemistry. With far-reaching applications in renewable energy and carbon mitigation, significant effort has been invested in the study of these complexes. In particular, computational approaches offer a unique perspective on how this enzyme functions at an electronic and atomistic level. In this article, we discuss state-of-the art quantum chemical methods and how they have helped deepen our comprehension of [NiFe] hydrogenase. We outline the key strategies that can be used to compute the (i) geometry, (ii) electronic structure, (iii) thermodynamics and (iv) kinetics properties associated with the enzymatic activity of [NiFe] hydrogenase and other bioinorganic complexes.
\end{abstract}

\section{INTRODUCTION}

Hydrogenases are remarkably efficient natural enzymes that catalyze the reversible oxidation of molecular hydrogen at ambient temperature and pressure $\left(\mathrm{H}_{2} \rightleftharpoons\right.$ $\left.2 \mathrm{H}^{+}+2 \mathrm{e}^{-}\right) \cdot[1-5]$ Since $\mathrm{H}_{2}$ is one of the most promising alternative energy sources, the understanding of how these redox enzymes function has the potential to prompt new clean energy technologies. Indeed, it has been proposed that artificial catalysts could be designed by mimicking, to some extent, hydrogenases.[6, 7] New photochemical technologies for large scale clean hydrogen production and oxidation could also be developed,[8-11] offering an elegant route to address the energy problem.

Although the detailed mechanism by which hydrogenases catalyze the oxidation of $\mathrm{H}_{2}$ has not been resolved in its entirety, the key steps of the reaction are known to be occurring at the metallic centers of the enzymes. Different metal atoms can be found in the active site, which define three types of hydrogenases: monometallic iron-only $([\mathrm{Fe}])$, bimetallic iron-iron ([FeFe] $)$ and nickeliron $([\mathrm{NiFe}])$. In this article, we will focus on the less known $[\mathrm{NiFe}]$ hydrogenase whose enzymatic function can be modulated by $\mathrm{pH}$ and redox potential.[1, 2] It is worth noting that, despite a common active site, there are structural differences between [NiFe] hydrogenase isolated from different organisms. These variants exhibit unique properties including aerobic hydrogen oxydation and preferential hydrogen production activity.[1]

Bioinorganic macromolecules such as [NiFe] hydrogenase are especially challenging to characterize experimentally.[12, 13] Too large for Nuclear Magnetic Resonance (NMR),[14-16] its structure was first determined using X-Ray diffraction (XRD) in conjunction with spectroscopic methods.[17-19] Three metallic centers were discovered in addition to the [NiFe] site: two $[4 \mathrm{Fe}-4 \mathrm{~S}]$ and one $[3 \mathrm{Fe}-4 \mathrm{~S}]$ whose role are to channel elec-

\footnotetext{
*tvan@mit.edu
}

trons to and from the active site. Metal complexes are in principal good candidates for magnetic resonance techniques such as Electron Nuclear DOuble Resonance (ENDOR)[20-22] or Electron Paramagnetic Resonance (EPR) [23-25]. Several redox states of the active site have been thus reported, although most of them catalytically inactive. Theoretical and computational methods provide another key to deepen our understanding of these kinds of systems. [26, 27] They assist and complement experimental techniques by providing atomistic and structural detail, even for structures that might be difficult to isolate experimentally. They also give insight into the electronic structure of the system, expanding on the information from EPR and ENDOR measurements. Theoretical approaches are thus uniquely placed to unveil the mysteries surrounding the functioning of [NiFe] hydrogenase.

In this article, we review how computational methods have and can be used to study this enzyme. We will summarize the various quantum chemistry techniques that give insight into the (i) geometry, (ii) electronic structure, (iii) thermodynamics and (iv) kinetics properties of [NiFe] hydrogenase. In the process, we will touch on a range of technical challenges wide enough to be relevant to most other bioinorganic complexes in a variety of other research fields such as enzymology,[28-32] genetics, [3337] regulation,[38-41] medicine[42-46] and environmental chemistry.[47-50]

\section{GEOMETRY OF THE HETEROBIMETALLIC ACTIVE SITE}

Although [NiFe] hydrogenase is made of tens of thousands atoms, only a few localized sites are directly involved in $\mathrm{H}_{2}$ oxidation, making them the focus of attention (see Figure 1).[51-54]

Following the identification of both iron and nickel in the active site, Fourier Transform InfraRed (FTIR) studies revealed the presence of carbon monoxide and cyanide ligands coordinating the iron.[55-57] Two cys- 


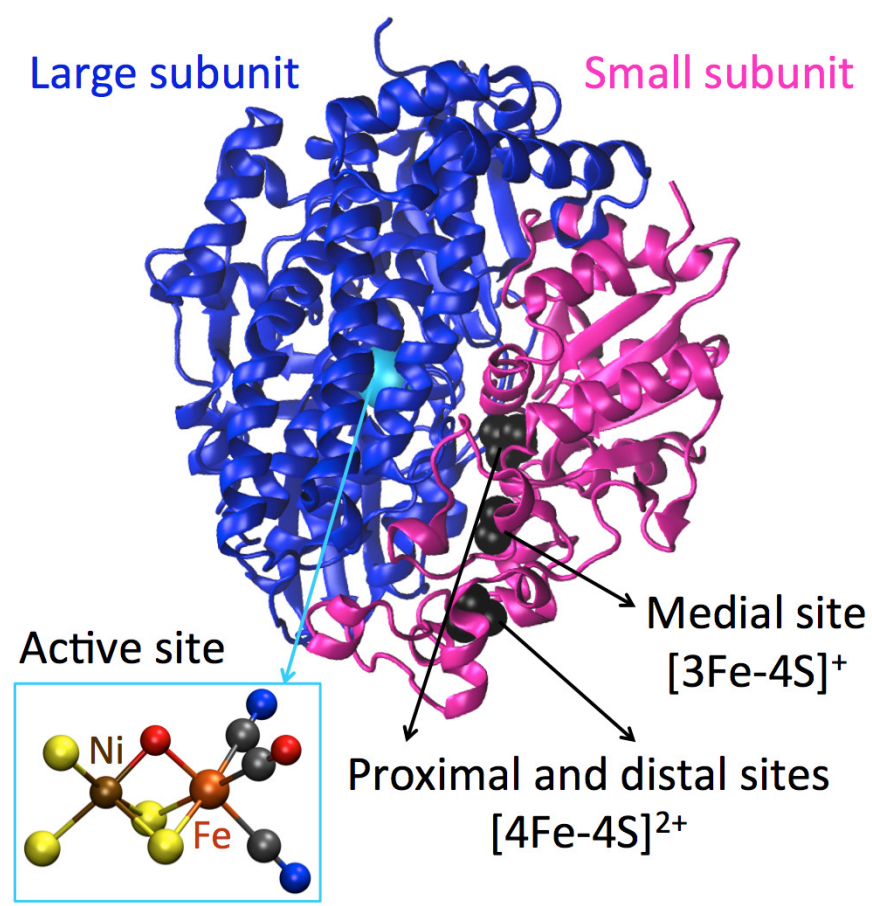

FIG. 1. The enzyme [NiFe] hydrogenase is an heterodimer with two unique subunits: one large ( $60 \mathrm{kDa}$ in blue) that contains the active site and one small ( $30 \mathrm{kDa}$ in pink) with three iron sulfur clusters channeling electrons from the surface of the protein to the active site. This figure was made using the deposited structure of the ready oxidized form of [NiFe] hydrogenase from Desulfovibrio fructosivorans (1YRQ).[51]

teine residues and two bridging cysteine anchor the metallic center to the rest of the protein. Other experimental studies have shown the occasional existence of an additional bridging species: $\mathrm{O}^{2-}$ (as in Figure 1), $\mathrm{OH}^{-}$ or $\mathrm{OOH}^{-} .[55,57-59]$ However, the relative stability of these various structures is not known from experiments, and neither are the precise locations of hydrogen species. Quantum Mechanical (QM) calculations can then help to refine and improve this picture; finding the most energetically favorable positions for substrate, protons and solvent molecules and also comparing the energies of different structures. Intermediates can also computed by optimizing the structure at different oxidation states.

Combined Quantum mechanical/Molecular Mechanics (QM/MM) offers the best compromise between accuracy and computational cost for this purpose.[60-62] In this case, the protein is split into a QM region (the nickel-iron active site) and a MM region (the rest of the protein). In the "mechanical embedding" or "subtractive" scheme[61, 63], the interaction between the QM and MM subsystems is computed at the MM level and the total energy of the system is calculated as follows:

$$
E_{\mathrm{tot}}=E^{\mathrm{QM}}(\mathrm{QM})+E^{\mathrm{MM}}(\mathrm{QM}+\mathrm{MM})-E^{\mathrm{MM}}(\mathrm{QM}) .
$$

This implies that the QM subsystem is not influenced by the MM point charges and the $\mathrm{QM} / \mathrm{MM}$ interaction is only due to steric constraints. In the more sophisticated "electronic embedding" or "additive" scheme[61, 63], the point charges of the MM region are added as an external potential to the QM Hamiltonian. This effectively polarizes the electron density by the field created by the MM environment and the total energy is computed according to:

$$
E_{\text {tot }}=E^{\mathrm{QM}+\mathrm{QM} / \mathrm{MM}}(\mathrm{QM})+E^{\mathrm{MM}}(\mathrm{MM}) .
$$

Note also that the use of a polarizable force field for the MM region can allow the MM subsystem to be in turn polarized by the QM region.[64-66] Although QM/MM optimization of the active site accounts for long range electrostatic effects, there remains the technical problem associated with the treatment of chemical bonds between the QM and MM regions. Here for example, the QM/MM boundary will inevitably cut through the covalently bound cysteine residues or through peptide linkages between one residue and another. One solution to this problem is to introduce dummy hydrogen atoms, invisible to the MM region, to saturate the dandling $\mathrm{QM}$ bonds. $[61,67,68]$ A more elaborate approach is to add link atoms using scaled down pseudopotentials with the required valence charge to preserve the electronic structure at the center of the active site. $[61,69]$

The accuracy of QM/MM methods also depends on the level of theory used for the QM and MM regions. In practice, DFT and empirical force fields are the most practical, hence popular, combination for such a macromolecule.[60, 70-72] Hybrid functionals in general, and B3LYP in particular, are often used in combination with at least a double zeta basis set to obtain reasonable accuracy. [2, 71] However, it has been shown that metal ligand distances could be overestimated by B3LYP when compared with XRD data. Noticeable improvements occur when reducing the fraction of exchange in the functional used, down to $5 \%$ in some cases.[73-76] Sometimes, a higher level pure QM calculation is performed on a small cluster derived from the QM/MM optimized structure to calculate spectroscopic parameters at better accuracy. $[60,70,72]$

In summary, QM/MM geometry optimization of the active site of $[\mathrm{NiFe}]$ hydrogenase greatly contributes to the interpretation of crystallographic data by finding the likely position of transient hydrogen atoms. Notably, calculations identified the now accepted heterolytic cleavage of $\mathrm{H}_{2}$ as the initial step of the reaction, whereby one hydrogen becomes a bridging hybride and the other a proton on a cysteine ligands. [51, 53, 77] The clear determination of the chemical nature of the ligands bridging the metal atoms has also helped to rationalize the various activation energy measured for different forms of [NiFe] hydrogenase. $[51,53]$ 


\section{ELECTRONIC STRUCTURE OF THE DIFFERENT REDOX STATES OF THE ACTIVE SITE}

To elucidate the reaction mechanism by which $[\mathrm{NiFe}]$ hydrogenase catalyzes the heterolytic cleavage of molecular hydrogen, a clear understanding of the different active site redox states is crucial. Figure 2 shows the consensus reached in the literature by combining experimental and theoretical approaches. The ferrous ion in the active

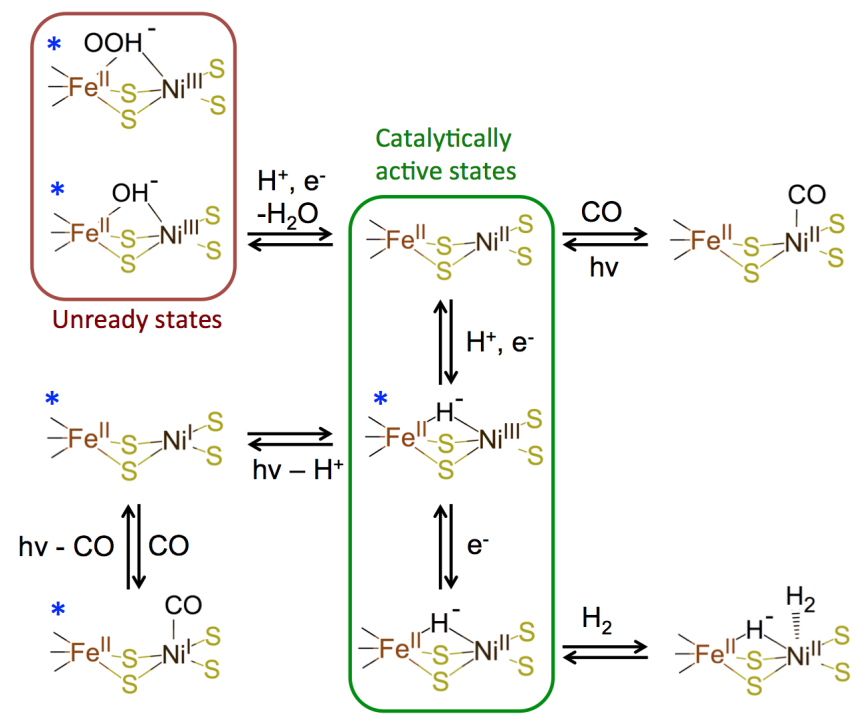

FIG. 2. Redox states of the active site of [NiFe] hydrogenase as characterized by experimental and/or theoretical methods. Many studies focus on the activation of the enzyme, i.e. the transition from unready (circled in brown) to catalytically active (circled in green) states. The EPR detectable states are marked by a dark blue star. Sketch adopted from [55].

site of $[\mathrm{NiFe}]$ hydrogenase is stabilized in a redox inactive low-spin state $(\mathrm{S}=0)$ by the strong field ligands, $\mathrm{CN}$ and CO, to which it is coordinated.[55, 78] This leaves the sulfur bound nickel responsible for the redox processes of the enzyme.[79-81] As shown in Figure 2, the catalytic forms of the active site involve two oxidation states of the nickel. EPR experiments recorded signal for $\mathrm{Ni}(\mathrm{III})$ of $\mathrm{S}=1 / 2[82-84]$ but controversy rose about the true spin state of $\mathrm{Ni}(\mathrm{II})$. Although experimental[85, 86] and theoretical[87, 88] studies reported the nickel to be low-spin, L-edge soft Xray and EXAFS experiments suggested a high spin $\mathrm{Ni}(\mathrm{II})$ instead.[89, 90] These findings were supported by theoretical studies[91-93] that demonstrate that only high spin nickel species lead to a distorted tetrahedral arrangement of the ligands around $\mathrm{Ni}$ as repeatedly found in the crystal structures of the active site of [NiFe] hydrogenase.[94-96]

Both metals are influenced by the changes in oxidation of the active site along the catalytic cycle. This suggests the presence of metal-metal interactions stabilizing the electronic states that promote the redox reaction with hydrogen. More specifically, anti-ferromagnetic interactions between the nickel and iron centers could lead to multiple low energy electronic states. Therefore, computational methods that predict the electronic as well as magnetic properties of metal containing clusters are extremely important for the study of [NiFe] hydrogenase.[97, 98] This includes the redox states of the iron-sulfur electron shuttles.

As a first approximation, DFT can be used for the electronic structure, providing a simple interpretation of the results. The unpaired electrons of metal atoms require an unrestricted formalism whereby the alpha and beta populations are treated with different potentials. Since $\mathrm{Fe}(\mathrm{II})$ is low-spin in the active site of [NiFe] hydrogenase, this is mostly relevant to the iron-sulfur clusters. Within this context, we note that the interactions between transition metal elements are typically described using the Heisenberg-Double-Exchange (HDE) hamiltonian:[99-102]

$H_{\mathrm{HDE}}=-2 J \hat{S}_{1} \hat{S}_{2}+\left[b\left(\hat{a}_{2 l \sigma}^{\dagger} \hat{a}_{1 l \sigma}+\hat{a}_{2 l(-\sigma)}^{\dagger} \hat{a}_{1 l(-\sigma)}\right)+\right.$ h.c. $]$,

where $J$ is the coupling, $b$ the double-exchange constant, $\hat{S}_{i}$ the spin operator for d-electrons in ion $i, \hat{a}_{i l \sigma}^{\dagger} \hat{a}_{j l \sigma}$ the hopping operators transferring the electron with spin $\sigma$ from the $l^{\text {th }} \mathrm{d}$-orbital of the $j^{\text {th }}$ ion to the $l^{\text {th }}$ d-orbital of the $i^{\text {th }}$ ion. Note that this Hamiltonian does not apply to mixed valence systems because it is assumed that each metal ion has fixed spin and charge states. Although there has been some work trying to generalize the model to mixed valence systems, the determination of what the relevant Hamiltonians are for these cases and how to parametrize them is an outgoing area of research.[103106] In the HDE model, the full ladder of pure spin state energies can be constructed once we know the value of the coupling constants. The couplings can often be extracted from magnetic susceptibility, although with some danger of over-fitting. The couplings can alternatively be extracted directly from Broken Symmetry Density Functional Theory (BS-DFT) calculations.[107-109] BSDFT has the clear advantage that it treats the antiferromagnetic coupling between spins localized on different atoms and the stronger metal-ligands and/or metal-metal bonds at the same level of theory. However, it suffers the same limitations on functional as explained in Section II. Overall, pure functionals will stabilize low spin states while hybrids will favor high spin ones. Consequently, the relative multiplet energies of a given intermediate, will vary almost linearly with the fraction of Hartree-Fock exchange.[73-76] Further, the energy computed is in fact a weighted average of the real spin state energies.[72, 107, 108, 110-113] Although some extensions of BSDFT exists,[114] efforts quickly converge towards the development of more "ab initio" methods that would more accurately predict pure spin state energies of strongly interacting metal containing clusters. The development of these models requires an electronic structure method that can deal with strongly correlated systems. A few studies have been done using minimal active 
spaces but these techniques are still restricted to very small groups of atoms such as $[2 \mathrm{Fe}-2 \mathrm{~S}]$ clusters. Others split the problem by performing Complete Active Space Self Consistent Field (CASSCF) calculations to extract the energies of a multitude of low lying states while treating dynamical correlation with a subsequent Multi Reference Configuration Interaction (MRCI) calculation for selected energy operations only.[115-119] Finally, purely $a b$ initio methods based on the Density Matrix Renormalization Group (DMRG) are being developed in the context of metal containing clusters.[106, 120-125] Recently, ab initio DMRG has been applied to the [4Fe-4S] cluster of [NiFe] hydrogenase.[106] Although the method is still limited to very small clusters, the study shows the importance of developing accurate electronic structure methods by demonstrating that commonly used models (like HDE) can underestimate the number of low-lying states, with direct implications for our understanding of the reactivity of metals in bioinorganic complexes.

Altogether, the BS-DFT and phenomenological HDE model has been used the most successfully for FeS clusters,[126-129] including instances where the model provided the basis to interpret experiments.[16, 130-132] The same success has not yet been made for the active site of $[\mathrm{NiFe}]$ hydrogenase where more robust methods are needed to carefully explore the reactivity of such an heterometallic enzyme.

\section{CALCULATION OF THERMODYNAMIC PROPERTIES}

The mechanism by which [NiFe] hydrogenase oxidizes molecular hydrogen involves a number of intermediate states, some of which are still poorly characterized. Figure 3 shows for example the elementary redox steps of two mechanisms that have been proposed in the literature.[55] The identification of the most likely scenario starts with the calculation of the driving force of each reaction. This is done by calculating the free energy change, or redox potential, associated with each step. These calculations require, at a bare minimum, ensemble averages of energy difference between reactant and product states. [133, 134]

Fast, accurate simulation of ensemble averages is one of the biggest challenges in computational chemistry. To obtain a meaningful sampling, accounting for entropic effects, many configurations must be computed and the results have to be interpreted within the statistical error associated with the finite simulation time. Since the proper sampling of canonical configurations of a solvated protein like [NiFe] hydrogenase is so demanding, classical Molecular Dynamics (MD) is often the method of choice.[135] However, the development of classical force fields for metalloproteins is difficult.[135, 136] In principle one can get statistics from fluctuations of conformations generated by $a b$ initio MD but this hugely increases the cost and can typically only be done for small clusters. More recently,
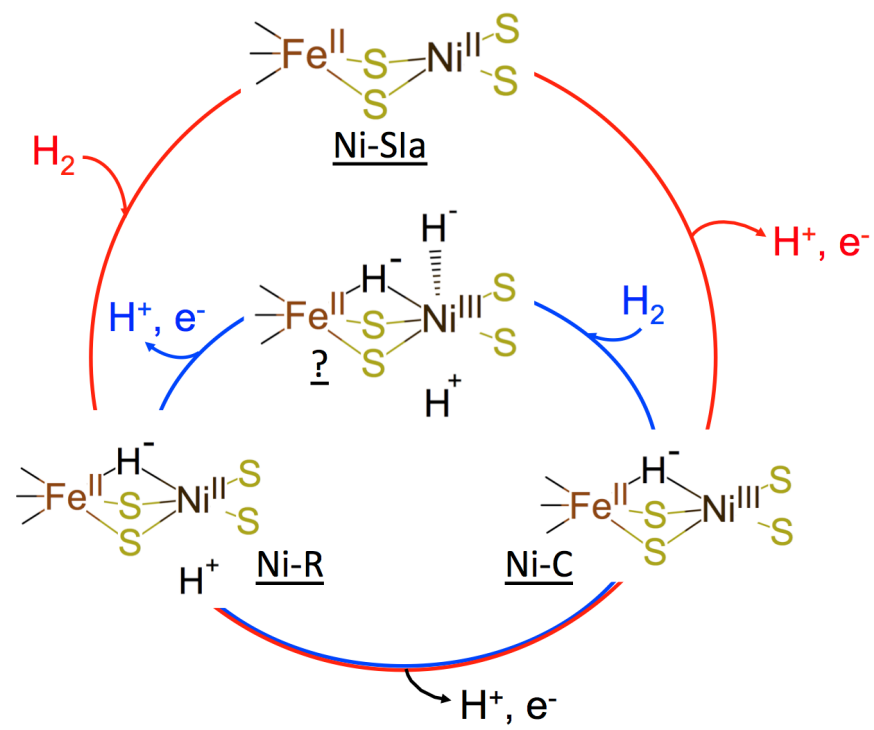

FIG. 3. Possible catalytic cycle of [NiFe] hydrogenase with two potential hydrogen acceptors. Although many studies agree on the presence of $\mathrm{Ni}-\mathrm{C}$ and $\mathrm{Ni}-\mathrm{R}$, there remains doubt about the completion of the cycle as well as the interconversion between each state.[55]

reactive $\mathrm{MD}$ have shown promise for the study of bioinorganic complexes.[137, 138] Although the implementation of reactive force fields also comes with significant computational challenges, the method has the clear advantage of accounting for bond breaking and forming by the incorporation of an empirical bond order potential.[138] Being able to calculate fundamental quantum properties while retaining the simplicity of classical MD would have a significant impact for the study of [NiFe] hydrogenase and large biological systems in general.[139-142]

The other main challenge in computing [NiFe] hydrogenase redox potentials is the calculation of the energy difference between oxidant and reductant. A popular method is the QM/MM Thermodynamic Cycle Perturbation (QTCP) approach where QM/MM is used to compute the energy differences on MD generated configurations. Note however, that QM/MM energy differences can only be rigorously calculated when the QM region consist of exactly the same atoms in both redox states. This is not always a trivial condition to satisfy, especially in $[\mathrm{NiFe}]$ hydrogenase where the redox reactions are mostly coupled to proton transfer.[77, 143] The adaptive QM/MM formalism alleviates this problem by enabling the transfer of atoms between the QM and MM regions thereby explicitly accounting for diffusion.[144, 145] Typically, in computing redox potentials a triple-zeta basis set will replace the double zeta standard used for QM/MM geometry optimization. Further improvements in accuracy can be reached by adding DFTD3 dispersion and/or QM/MM corrections. Despite these efforts, it has been observed that free energies of reaction thus calculated strongly depend on the size of the QM 
subsystem.[71, 146, 147]. To address this issue, a new procedure has been developed whereby QM/MM geometry optimization is used on the MD produced snapshots and pure QM energy calculations are subsequently done on bigger clusters as illustrated in Figure 4. Here, the

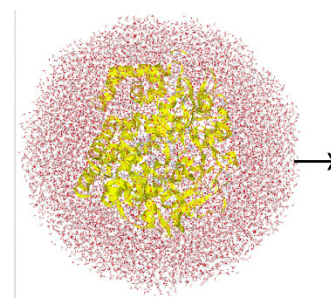

MD

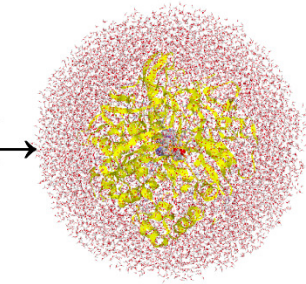

$\mathrm{QM} / \mathrm{MM}$

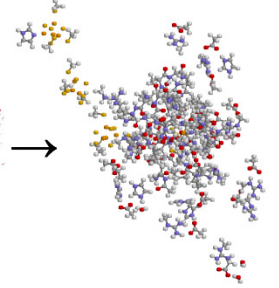

930-atom QM
FIG. 4. "Big-QM" energy calculation on the active site of [NiFe] hydrogenase whose structure was optimized with standard QM/MM methods. This calculation scheme aims to prevent the dependence of the calculated energies on the size of the QM system. Reprinted with permission from J. Chem. Theory Comput. 2013, 9, 640-649. Copyright 2013 American Chemical Society. The big QM calculations are single point energies performed at the BP86/def2- SV(P) level that were then extrapolated to the B3LYP/def2-TZVP level with a smaller QM system, and zero-point energy, entropy, and thermal effects were added.

"big-QM" cluster is about one thousand atoms and includes all chemical groups within a certain distance (typically $5 \AA$ ) of the model active site as well as all the buried charges and moving junctions at most two residues away from the active site. [71, 148] Such large QM clusters likely exhibit many local minima that require extensive sampling. However, the proper sampling of wide and rugged energy landscapes is highly non trivial and remains an outstanding issue.

Overall, several studies on [NiFe] hydrogenase have shown that it is demanding to calculate accurate and reproducible reaction energies.[71, 149-152] At best, energies with an accuracy of $20 \mathrm{~kJ} / \mathrm{mol}$ have be obtained with QTCP.[71, 143, 146, 147] To resolve this issue, it has been rationalized that extensive sampling, polarization, short-range electrostatics, charge transfer and/or exchange repulsion may need to be accounted for to provide accurate reaction energies, which remains a significant challenge driving intense research efforts.[148, 153]

\section{KINETICS}

Free energies of reaction have to be combined with kinetic rates to fully rationalize the reaction mechanism of the oxidation of molecular hydrogen by [NiFe] hydrogenase. For thermally activated processes, it is usually sufficient to compute the activation barrier between reactants and products as illustrated in Figure 5. Note that these barriers are going to be influenced by environmental factors such as the acceptor pKa, the redox energies of surrounding groups, etc. Two groups of methods can be used to compute barrier heights: (i) those which compute the free energy landscape and (ii) those which compute minimum energy paths.

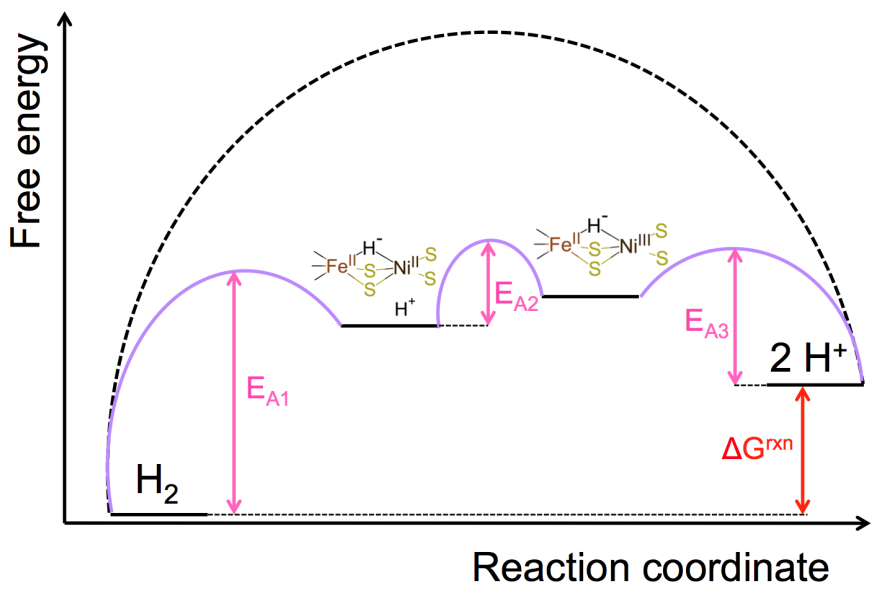

FIG. 5. Free energy profile of the oxidation of $H_{2}$ along an arbitrary reaction coordinates. The overall reaction is characterized by the driving force $\Delta G^{\mathrm{rxn}}$ and [NiFe] hydrogenase introduces two intermediates associated with relatively small energy barriers, $E_{A 1}, E_{A 2}$ and $E_{A 3}$. The driving force and energy barriers are pseudo-local properties that depend on the redox energy of the neighboring iron-sulfur clusters as well as the acceptor pKa.

Free energy landscape calculation requires the phase space to be reduced to a computationally tractable configuration space by selecting the few key coordinates that describe the reaction. The difficulty here is that the results will then depend on the choice made to select these coordinates (specific cartesian coordinates or collective variables) describing the reduced space. This means that different mechanisms can be found "most likely" and compromise the overall validity of the studies. In some cases however, the choice is rather intuitive. If characterizing the elementary step between the Ni-SIa and Ni-R states for example (Figure 3), one may want to express the free energies of the compounds in the space spanned by the distance between the hydrogen and the iron and/or nickel atoms. Once the coordinates are chosen, enhanced sampling methods such as umbrella sampling[154-158] and Replica Exchange Molecular Dynamics (REMD)[159-162] can be used to calculate the barrier height between reactants and products. Nevertheless, metadynamics, which increases the sampling of high energy regions of the collective variable via a bias potential, is the technique the most often used.[163-169]

The minimum energy path is a promising alternative to enhanced sampling because it does not require the selection of a reaction coordinate. Rather, several images (or states) of the reactants and products are generated, connected together and minimized to trace out a path. Such "chain-of-states" techniques include the Nudge Elastic Band (NEB) method where the images are connected by 
harmonic spring forces that ensure an even distribution of the resulting path,[170-174] the growing string method [175-179] and the freezing string method [180-182]. The weakness of these techniques is that they are only based on the internal energy, not the free energy, of the system. Thus, for cases where entropic effects (such as solvent reorganization) are significant, path finding methods are less appropriate.

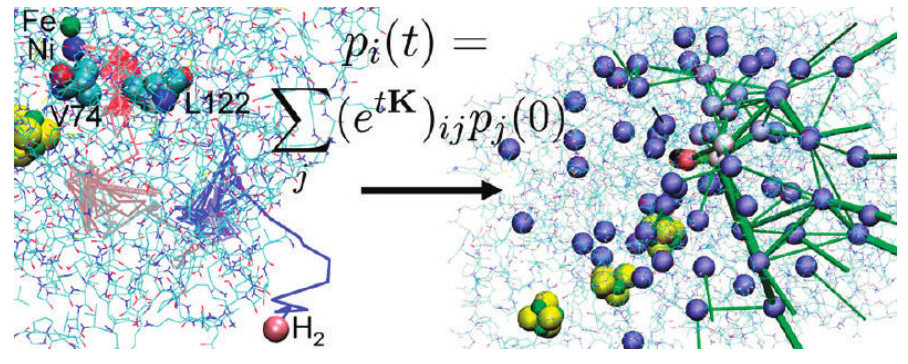

FIG. 6. Small molecule transport kinetics is essential to the enzymatic activity of many proteins. Nevertheless few theoretical methods allow the accurate calculation of diffusion rates. Reprinted with permission from J. Am. Chem. Soc. 2011, 133, 3548-3556. Copyright 2011 American Chemical Society.

\section{CONCLUSION}

In this article, we presented a series of illustrations of how the fundamental properties associated with the enzymatic activity of [NiFe] hydrogenase can be analyzed using computational chemistry. In particular, we noted that computation has played a crucial role in establishing the positions of hydrogens and bridging ligands at the active site, understanding the magnetic parameters of FeS clusters that shuttle charges and describing the mechanism of substrate delivery to the heterobimetallic core. There remains a great deal that is still not understood about this enzyme and future computational efforts will be aimed at harmonizing the mass of experimental data to present a functioning atomistic model of this enzyme. Although our narrative was centered around $[\mathrm{NiFe}]$ hydrogenase, it is worth emphasizing that the approaches discussed in this article are transferable to other bioinorganic macromolecules. Both the size and the presence of metal atoms represent considerable challenges for most computational techniques. Calculations that are routinely done on other systems, such as geometry optimizations, are thus comparatively difficult for large metal-containing enzymes. However, as this review demonstrates, difficult is not the same as impossible. We hope that the work presented here will provide the inspiration for further computational investigations of enzyme mechanism and function in complexes like [NiFe] hydrogenase.

\section{ACKNOWLEDGMENTS}

This work was supported by a grant from the National Science Foundation (CHE-1464804).
[1] H. S. Shafaat, O. Rudiger, H. Ogata and W. Lubitz, BBA-Bioenergetics, 2013, 1827, 986 - 1002.
[2] M. Stein and W. Lubitz, Curr. Opin. Chem. Biol., 2002, 6, $243-249$. 
[3] M. Frey, ChemBioChem, 2002, 3, 153-160.

[4] C. Tard and C. J. Pickett, Chem. Rev., 2009, 109, 22452274 .

[5] W. Zhu, A. C. Marr, Q. Wang, F. Neese, D. J. E. Spencer, A. J. Blake, P. A. Cooke, C. Wilson and M. Schrder, Proc. Natl. Acad. Sci., 2005, 102, 1828018285 .

[6] J. Barber, Chem. Soc. Rev., 2009, 38, 185-196.

[7] A. Melis and T. Happe, Plant Physiology, 2001, 127, $740-748$.

[8] C. Sanchez, H. Arribart and M. M. Giraud Guille, Nat. Mater., 2005, 4, 277-288.

[9] H. Zhou, X. Li, T. Fan, F. E. Osterloh, J. Ding, E. M. Sabio, D. Zhang and Q. Guo, Adv. Mater., 2010, 22, 951-956.

[10] D. Walther, M. Ruben and S. Rau, Coord. Chem. Rev., 1999, 182, $67-100$.

[11] L. M. Utschig, S. C. Silver, K. L. Mulfort and D. M. Tiede, J. Am. Chem. Soc., 2011, 133, 16334-16337.

[12] J. Frazzon and D. R. Dean, Curr. Opin. Chem. Biol., 2003, 7, $166-173$.

[13] H. Beinert, R. H. Holm and E. Münck, Science, 1997, 277, 653-659.

[14] B. E. Barton, C. M. Whaley, T. B. Rauchfuss and D. L. Gray, J. Am. Chem. Soc., 2009, 131, 6942-6943.

[15] A. S. Lipton, T. A. Wright, M. K. Bowman, D. L. Reger and P. D. Ellis, J. Am. Chem. Soc., 2002, 124, 58505860 .

[16] I. Bertini, F. Briganti, C. Luchinat, A. Scozzafava and M. Sola, J. Am. Chem. Soc., 1991, 113, 1237-1245.

[17] P. M. Matias, C. M. Soares, L. M. Saraiva, R. Coelho, J. Morais, J. Le Gall and M. A. Carrondo, J. Bio. Inorg. Chem., 2001, 6, 63-81.

[18] Y. Higuchi, H. Ogata, K. Miki, N. Yasuoka and T. Yagi, Structure, 1999, 7, $549-556$.

[19] H. Ogata, S. Hirota, A. Nakahara, H. Komori, N. Shibata, T. Kato, K. Kano and Y. Higuchi, Structure, 2005, 13, $1635-1642$.

[20] S. Foerster, M. v. Gastel, M. Brecht and W. Lubitz, J. Bio. Inorg. Chem., 2005, 10, 51-62.

[21] C. Geßner, M. Stein, S. P. J. Albracht and W. Lubitz, J. Bio. Inorg. Chem., 1999, 4, 379-389.

[22] M. van Gastel, M. Stein, M. Brecht, O. Schröder, F. Lendzian, R. Bittl, H. Ogata, Y. Higuchi and W. Lubitz, J. Bio. Inorg. Chem., 2006, 11, 41-51.

[23] O. Trofanchuk, M. Stein, C. Geßner, F. Lendzian, Y. Higuchi and W. Lubitz, J. Bio. Inorg. Chem., 2000, 5, 36-44.

[24] M. Teixeira, I. Moura, A. V. Xavier, J. J. Moura, J. LeGall, D. V. DerVartanian, H. D. Peck and B. H. Huynh, J. Bio. Chem., 1989, 264, 16435-16450.

[25] S. Foerster, M. Stein, M. Brecht, H. Ogata, Y. Higuchi and W. Lubitz, J. Am. Chem. Soc., 2003, 125, 83-93.

[26] M. Podewitz, M. T. Stiebritz and M. Reiher, Faraday Discuss., 2011, 148, 119-135.

[27] B. Kirchner, F. Wennmohs, S. Ye and F. Neese, Curr. Opin. Chem. Biol., 2007, 11, $134-141$.

[28] B. R. Duffus, T. L. Hamilton, E. M. Shepard, E. S. Boyd, J. W. Peters and J. B. Broderick, Biochim. Biophys. Acta, Proteins Proteomics, 2012, 1824, 1254 $-1263$.

[29] S. J. Ullrich and C. Glaubitz, Acc. Chem. Res., 2013, 46, 2164-2171.
[30] S. E. J. Bowman, J. Bridwell-Rabb and C. L. Drennan, Acc. Chem. Res., 2016, 49, 695-702.

[31] G. Bender, E. Pierce, J. A. Hill, J. E. Darty and S. W. Ragsdale, Metallomics, 2011, 3, 797-815.

[32] T. G. Gray, A. S. Veige and D. G. Nocera, J. Am. Chem. Soc., 2004, 126, 9760-9768.

[33] D. Koenig and D. Weigel, Nature Rev. Genet., 2015, 16, $285-298$.

[34] D. S. Sharada, A. H. Shinde, S. M. Patel and S. Vidyacharan, J. Org. Chem., 2016, 81, 6463-6471.

[35] W. GH, M. A and K. R. M, Appl. Environ. Microbien., 2016, 82, $4613-4627$.

[36] J. Saberzadeh, R. Arabsolghar and M. A. Takhshid, Brain Res., 2016, 1635, 153 - 160.

[37] J. Prieto, P. Redondo, N. Merino, M. Villate, G. Montoya, F. J. Blanco and R. Molina, Acta Crystallogr. Sect. F, 2016, 72, 473-479.

[38] E. Oheix, N. Spencer, L. A. Gethings and A. F. A. Peacock, Z. Anorg. Allg. Chem., 2013, 639, 1370-1383.

[39] A. Robert, Y. Liu, M. Nguyen and B. Meunier, Acc. Chem. Res., 2015, 48, 1332-1339.

[40] M. Sochor, N. Baquer and P. McLean, Enzyme, 1982, 27, 149155.

[41] T. Nabeshima, Coord. Chem. Rev., 1996, 148, $151-$ 169.

[42] D. A. Dias, K. A. Kouremenos, D. J. Beale, D. L. Callahan and O. A. H. Jones, BioMetals, 2016, 29, 1-13.

[43] Y. Yang, R. Ouyang, L. Xu, N. Guo, W. Li, K. Feng, L. Ouyang, Z. Yang, S. Zhou and Y. Miao, J. Coord. Chem., 2015, 68, 379 - 397.

[44] J. Gailer, J. Inorg. Biochem., 2012, 108, 128 - 132.

[45] E. Zeini Jahromi and J. Gailer, Dalton Trans., 2010, 39, 329-336.

[46] N. A. Smith and P. J. Sadler, Phil. Trans. R. Soc. A, 2013, 371, year.

[47] E. Gumienna-Kontecka, V. M. Nurchi, A. Szebesczyk, P. Bilska, K. Krzywoszynska and H. Kozlowski, Z. Anorg. Allg. Chem., 2013, 639, 1321-1331.

[48] A.-F. Ngomsik, A. Bee, M. Draye, G. Cote and V. Cabuil, C. R. Chim., 2005, 8, $963-970$.

[49] X. Wu, S. J. Cobbina, G. Mao, H. Xu, Z. Zhang and L. Yang, Environ. Sci. Pollut. Res., 2016, 23, 82448259 .

[50] W. Maret and J.-M. Moulis, in The Bioinorganic Chemistry of Cadmium in the Context of Its Toxicity, ed. A. Sigel, H. Sigel and R. K. Sigel, Springer Netherlands, Dordrecht, 2013, pp. 1-29.

[51] A. Volbeda, L. Martin, C. Cavazza, M. Matho, B. W. Faber, W. Roseboom, S. P. J. Albracht, E. Garcin, M. Rousset and J. C. Fontecilla-Camps, J. Biol. Inorg. Chem., 2005, 10, 239-249.

[52] H. Ogata, P. Kellers and W. Lubitz, J. Mol. Biol., 2010, 402, $428-444$.

[53] F. A. Armstrong, Curr. Opin. Chem. Biol., 2004, 8, 133 $-140$.

[54] M. Horch, P. Hildebrandt and I. Zebger, Phys. Chem. Chem. Phys., 2015, 17, 18222-18237.

[55] S. Kaur-Ghumaan and M. Stein, Dalton Trans., 2014, 43, 9392-9405.

[56] H. Ogata, W. Lubitz and Y. Higuchi, Dalton Trans., 2009, 7577-7587.

[57] F. A. Armstrong and S. P. Albracht, Phil. Trans. R. Soc. A, 2005, 363, 937-954. 
[58] M.-E. Pandelia, V. Fourmond, P. Tron-Infossi, E. Lojou, P. Bertrand, C. Leger, M.-T. Giudici-Orticoni and W. Lubitz, J. Am. Chem. Soc., 2010, 132, 6991-7004.

[59] A. Volbeda, M.-H. Charon, C. Piras, E. C. Hatchikian, M. Frey and J. C. Fontecilla-Camps, Nature, 1995, 373, 580-587.

[60] C. Greco, V. Fourmond, C. Baffert, P.-h. Wang, S. Dementin, P. Bertrand, M. Bruschi, J. Blumberger, L. de Gioia and C. Leger, Energy Environ. Sci., 2014, 7, 3543-3573.

[61] E. Brunk and U. Rothlisberger, Chem. Rev., 2015, 115, 6217-6263.

[62] A. Warshel and M. Levitt, J. Mol. Biol., 1976, 103, 227 -249 .

[63] T. Vreven, K. Morokuma, . Farkas, H. B. Schlegel and M. J. Frisch, J. Comput. Chem., 2003, 24, 760-769.

[64] H. M. Senn and W. Thiel, Angew. Chem. Int. Ed., 2009, 48, 1198-1229.

[65] J. Gao, J. Comput. Chem., 1997, 18, 1061-1071.

[66] M. Elstner, T. Frauenheim and S. Suhai, J. Mol. Struc.-Theochem, 2003, 632, $29-41$.

[67] Y.-P. Pang, Proteins: Struct., Funct., Bioinf., 2001, 45, 183-189.

[68] T. Woo, P. Margl, L. Deng, L. Cavallo and T. Ziegler, Catal. Today, 1999, 50, $479-500$.

[69] T. K. Woo, P. M. Margl, P. E. Blochl and T. Ziegler, J. Phys. Chem. B, 1997, 101, 7877-7880.

[70] U. Ryde, Dalton Trans., 2007, 607-625.

[71] G. Dong and U. Ryde, J. Bio. Inorg. Chem., 2016, 21, 383-394.

[72] A. Volbeda, P. Amara, C. Darnault, J.-M. Mouesca, A. Parkin, M. M. Roessler, F. A. Armstrong and J. C. Fontecilla-Camps, Proc. Natl. Acad. Sci., 2012, 109, 5305-5310.

[73] J. A. Wolny, H. Paulsen, A. X. Trautwein and V. Schnemann, Coord. Chem. Rev., 2009, 253, 2423 - 2431.

[74] M. Reiher, Inorg. Chem., 2002, 41, 6928-6935.

[75] M. Reiher, O. Salomon and B. Artur Hess, Theor. Chem. Acc., 2001, 107, 48-55.

[76] M. Pavlov, M. R. A. Blomberg and P. E. M. Siegbahn, International Journal of Quantum Chemistry, 1999, 73, 197-207.

[77] S. O. N. Lill and P. E. M. Siegbahn, Biochem., 2009, 48, 1056-1066.

[78] L. De Gioia, P. Fantucci, B. Guigliarelli and P. Bertrand, Inorg. Chem., 1999, 38, 2658-2662.

[79] W. Lubitz, E. Reijerse and M. van Gastel, Chem. Rev., 2007, 107, 4331-4365.

[80] K. Weber, . F. Erdem, E. Bill, T. Weyhermuller and W. Lubitz, Inorg. Chem., 2014, 53, 6329-6337.

[81] Z. Li, Y. Ohki and K. Tatsumi, J. Am. Chem. Soc., 2005, 127, 8950-8951.

[82] R. Cammack, D. Patil, R. Aguirre and E. Hatchikian, \{FEBS $\}$ Lett., 1982, 142, $289-292$.

[83] V. M. Fernandez, E. Hatchikian and R. Cammack, BBA-Protein Struct. M., 1985, 832, $69-79$.

[84] J. Moura, I. Moura, B. Huynh, H.-J. Krger, M. Teixeira, R. DuVarney, D. DerVartanian, A. Xavier, H. P. Jr. and J. LeGall, J. Biochem. Biophys. Res. Commun., 1982, 108, $1388-1393$.

[85] A. T. Kowal, I. C. Zambrano, I. Moura, J. J. Moura, J. LeGall and M. K. Johnson, Inorg. Chem., 1988, 27, 1162-1166.
[86] C.-P. Wang, R. Franco, J. Moura, I. Moura and E. Day, J. Biol. Chem., 1992, 267, 7378-7380.

[87] P. E. Siegbahn and M. R. Blomberg, Chem. Rev., 2000, 100, 421-438.

[88] S. Niu, L. M. Thomson and M. B. Hall, J. Am. Chem. Soc., 1999, 121, 4000-4007.

[89] H. Wang, C. Ralston, D. Patil, R. Jones, W. Gu, M. Verhagen, M. Adams, P. Ge, C. Riordan, C. Marganian et al., J. Am. Chem. Soc., 2000, 122, 10544-10552.

[90] W. Gu, L. Jacquamet, D. Patil, H. Wang, D. Evans, M. Smith, M. Millar, S. Koch, D. Eichhorn, M. Latimer et al., J. Inorg. Biochem., 2003, 93, 41-51.

[91] A. Pardo, A. L. De Lacey, V. M. Fernández, H.-J. Fan, Y. Fan and M. B. Hall, J. Biol. Inorg. Chem., 2006, 11, 286-306.

[92] H.-J. Fan and M. B. Hall, J. Am. Chem. Soc., 2002, 124, 394-395.

[93] M. Bruschi, L. De Gioia, G. Zampella, M. Reiher, P. Fantucci and M. Stein, J. Biol. Inorg. Chem., 2004, 9, 873-884.

[94] A. Volbeda, M.-H. Charon, C. Piras, E. C. Hatchikian et al., Nature, 1995, 373, 580.

[95] Y. Higuchi, T. Yagi and N. Yasuoka, Structure, 1997, 5, 1671-1680.

[96] Y. Higuchi, H. Ogata, K. Miki, N. Yasuoka and T. Yagi, Structure, 1999, 7, 549-556.

[97] M. Kampa, M.-E. Pandelia, W. Lubitz, M. van Gastel and F. Neese, J. Am. Chem. Soc., 2013, 135, 3915-3925.

[98] P. A. Lindahl, J. Inorg. Biochem., 2012, 106, $172-178$.

[99] W. Heisenberg, Z. Phys., 1928, 49, 619-636.

[100] P. A. M. Dirac, Proc. R. Soc. London A, 1929, 123, 714-733.

[101] J. H. Van Vleck, Rev. Mod. Phys., 1945, 17, 27-47.

[102] P. Labeguerie, C. Boilleau, R. Bastardis, N. Suaud, N. Guihery and J.-P. Malrieu, J. Chem. Phys., 2008, 129 ,.

[103] M. Belinskii, Mol. Phys., 1987, 60, 793-819.

[104] X.-Q. Ding, E. L. Bominaar, E. Bill, H. Winkler, A. X. Trautwein, S. Drueke, P. Chaudhuri and K. Wieghardt, J. Chem. Phys., 1990, 92, 178-186.

[105] A. I. Gaudette, I.-R. Jeon, J. S. Anderson, F. Grandjean, G. J. Long and T. D. Harris, J. Am. Chem. Soc., 2015, 137, 12617-12626.

[106] S. Sharma, K. Sivalingam, F. Neese and C. Kin-Lic, Nat. Chem., 2014, 6, 927-933.

[107] L. Noodleman, J. Chem. Phys., 1981, 74, 5737-5743.

[108] L. Noodleman and J. G. Norman, J. Chem. Phys., 1979, 70, 4903-4906.

[109] K. Yamaguchi, Chem. Phys. Lett., 1975, 33, 330 - 335.

[110] V. Pelmenschikov and M. Kaupp, J. Am. Chem. Soc., 2013, 135, 11809-11823.

[111] J.-M. Mouesca, in Density Functional Theory-Broken Symmetry (DFT-BS) Methodology Applied to Electronic and Magnetic Properties of Bioinorganic Prosthetic Groups, ed. J. C. Fontecilla-Camps and Y. Nicolet, Humana Press, Totowa, NJ, 2014, pp. 269-296.

[112] S. G. Tabrizi, V. Pelmenschikov, L. Noodleman and M. Kaupp, J. Chem. Theory Comput., 2016, 12, 174187.

[113] M.-E. Pandelia, D. Bykov, R. Izsak, P. Infossi, M.-T. Giudici-Orticoni, E. Bill, F. Neese and W. Lubitz, Proc. Natl. Acad. Sci., 2013, 110, 483-488. 
[114] M. Barborini and L. Guidoni, J. Chem. Phys., 2016, 145 .

[115] O. Hubner and J. Sauer, J. Chem. Phys., 2002, 116, 617-628.

[116] B. O. Roos, in The Complete Active Space Self-Consistent Field Method and its Applications in Electronic Structure Calculations, John Wiley and Sons, Inc., 2007, pp. 399-445.

[117] M. G. Delcey, K. Pierloot, Q. M. Phung, S. Vancoillie, R. Lindh and U. Ryde, Phys. Chem. Chem. Phys., 2014, 16, 7927-7938.

[118] D. S. Kaliakin, R. R. Zaari and S. A. Varganov, J. Phys. Chem. A, 2015, 119, 1066-1073.

[119] R. L. Yson, J. L. Gilgor, B. A. Guberman and S. A. Varganov, Chem. Phys. Lett., 2013, 577, 138 - 141.

[120] S. R. White and R. L. Martin, J. Chem. Phys., 1999, 110, 4127-4130.

[121] G. K.-L. Chan and S. Sharma, Annu. Rev. Phys. Chem., 2011, 62, 465-481.

[122] G. K.-L. Chan and M. Head-Gordon, J. Chem. Phys., 2002, 116, 4462-4476.

[123] Y. Kurashige and T. Yanai, J. Chem. Phys., 2009, 130, year.

[124] K. H. Marti, I. M. Ondk, G. Moritz and M. Reiher, J. Chem. Phys., 2008, 128, year.

[125] Q. M. Phung, S. Wouters and K. Pierloot, J. Chem. Theory Comput., 2016, 12, 4352-4361.

[126] L. Noodleman and E. J. Baerends, J. Am. Chem. Soc., 1984, 106, 2316-2327.

[127] L. Noodleman and E. R. Davidson, Chem. Phys., 1986, 109, $131-143$.

[128] G. Blondin and J. J. Girerd, Chem. Rev., 1990, 90, $1359-1376$

[129] J.-J. Girerd, J. Chem. Phys., 1983, 79, 1766-1775.

[130] V. Papaefthymiou, M. M. Millar and E. Muenck, Inorg. Chem., 1986, 25, 3010-3014.

[131] L. Banci, I. Bertini, F. Briganti, C. Luchinat, A. Scozzafava and M. V. Oliver, Inorg. Chem., 1991, 30, 45174524.

[132] G. Rius and B. Lamotte, J. Am. Chem. Soc., 1989, 111, 2464-2469.

[133] L.-P. Wang and T. Van Voorhis, J. Chem. Theory Comput., 2012, 8, 610-617.

[134] V. Vaissier and T. Van Voorhis, J. Chem. Theory Comput., 2016, 12, 5111-5116.

[135] D. M. A. Smith, Y. Xiong, T. P. Straatsma, K. M. Rosso and T. C. Squier, J. Chem. Theory Comput., 2012, 8, 2103-2114.

[136] V. H. Teixeira, A. M. Baptista and C. M. Soares, Biophys. J., 2006, 91, 2035 - 2045.

[137] C. Zou, S. Raman and A. C. van Duin, J. Phys. Chem. B, 2014, 118, 6302-6315.

[138] A. C. T. van Duin, S. Dasgupta, F. Lorant and W. A. Goddard, J. Phys. Chem. A, 2001, 105, 9396-9409.

[139] M. Iannuzzi, A. Laio and M. Parrinello, Phys. Rev. Lett., 2003, 90, 238302.

[140] H. Aktulga, J. Fogarty, S. Pandit and A. Grama, Parallel Comput., 2012, 38, $245-259$.

[141] K. Chenoweth, A. C. T. van Duin and W. A. Goddard, J. Phys. Chem. A, 2008, 112, 1040-1053.

[142] E. C. Neyts, A. C. T. van Duin and A. Bogaerts, J. Am. Chem. Soc., 2011, 133, 17225-17231.

[143] S. Sumner, P. Soderhjelm and U. Ryde, J. Chem. Theory Comput., 2013, 9, 4205-4214.
[144] K. Park, A. W. Gotz, R. C. Walker and F. Paesani, J. Chem. Theory Comput., 2012, 8, 2868-2877.

[145] S. Pezeshki and H. Lin, J. Chem. Theory Comput., 2015, 11, 2398-2411.

[146] L. Hu, J. Eliasson, J. Heimdal and U. Ryde, J. Phys. Chem. A, 2009, 113, 11793-11800.

[147] L. Hu, P. Soderhjelm and U. Ryde, J. Chem. Theory Comput., 2011, 7, 761-777.

[148] L. Hu, P. Saderhjelm and U. Ryde, J. Chem.Theory Comput., 2013, 9, 640-649.

[149] P. E. M. Siegbahn, J. W. Tye and M. B. Hall, Chem. Rev., 2007, 107, 4414-4435.

[150] M. Kampa, W. Lubitz, M. van Gastel and F. Neese, J. Biol. Inorg. Chem., 2012, 17, 1269-1281.

[151] P. Soderhjelm and U. Ryde, J. Mol. Struct. Theochem, 2006, 770, $199-219$.

[152] T. H. Rod and U. Ryde, Phys. Rev. Lett., 2005, 94, 138302 .

[153] R. A. Friesner and M. D. Beachy, Curr. Opin. Struct. Biol., 1998, 8, $257-262$.

[154] M. Souaille and B. Roux, Comput. Phys. Commun., 2001, 135, $40-57$.

[155] D. Hamelberg, J. Mongan and J. A. McCammon, J. Chem. Phys., 2004, 120, 11919-11929.

[156] K. Shing and K. Gubbins, Mol. Phys., 1981, 43, 717721.

[157] J. Kastner, Wiley Interdiscip. Rev. Comput. Mol. Sci., 2011, 1, 932-942.

[158] C. Bartels and M. Karplus, J. Phys. Chem. B, 1998, 102, 865-880.

[159] L. Xu, X. Wang and X. Wang, Eur. Biophys. J., 2013, 42, 575-586.

[160] K. Tai, Biophys. Chem., 2004, 107, $213-220$.

[161] J. Zhu, H. Fan, X. Periole, B. Honig and A. E. Mark, Proteins: Struct., Funct., Bioinf., 2008, 72, 1171-1188.

[162] Y. Sugita and Y. Okamoto, Chem. Phys. Lett., 1999, 314, $141-151$.

[163] A. Laio and F. L. Gervasio, Rep. Prog. Phys., 2008, 71, 126601.

[164] B. Ensing, M. De Vivo, Z. Liu, P. Moore and M. L. Klein, Acc. Chem. Res., 2006, 39, 73-81.

[165] A. Barducci, M. Bonomi and M. Parrinello, Wiley Interdiscip. Rev. Comput. Mol. Sci., 2011, 1, 826-843.

[166] A. Laio, A. Rodriguez-Fortea, F. L. Gervasio, M. Ceccarelli and M. Parrinello, J. Phys. Chem. B, 2005, 109, 6714-6721.

[167] G. Bussi, A. Laio and M. Parrinello, Phys. Rev. Lett., 2006, 96, 090601.

[168] A. Barducci, G. Bussi and M. Parrinello, Phys. Rev. Lett., 2008, 100, 020603.

[169] I. Sumner and G. A. Voth, J. Phys. Chem. B, 2012, 116, 2917-2926.

[170] G. Mills and H. Jónsson, Phys. Rev. Lett., 1994, 72, 1124-1127.

[171] G. Henkelman and H. Jonsson, J. Chem. Phys., 2000, 113, 9978-9985.

[172] G. Henkelman, B. P. Uberuaga and H. Jnsson, J. Chem. Phys., 2000, 113, 9901-9904.

[173] H. M. Senn and W. Thiel, Curr. Opin. Chem. Biol., 2007, 11, $182-187$.

[174] J.-W. Chu, B. L. Trout and B. R. Brooks, J. Chem. Phys., 2003, 119, 12708-12717.

[175] B. Peters, A. Heyden, A. T. Bell and A. Chakraborty, J. Chem. Phys., 2004, 120, 7877-7886. 
[176] W. Quapp, J. Chem. Phys., 2005, 122,.

[177] A. Goodrow, A. T. Bell and M. Head-Gordon, J. Chem. Phys., 2009, 130,.

[178] P. M. Zimmerman, J. Chem. Phys., 2013, 138,.

[179] W. Quapp, J. Comput. Chem., 2007, 28, 1834-1847.

[180] A. Behn, P. M. Zimmerman, A. T. Bell and M. HeadGordon, J. Chem. Phys., 2011, 135,.

[181] S. Mallikarjun Sharada, P. M. Zimmerman, A. T. Bell and M. Head-Gordon, J. Chem. Theory Comput., 2012, 8, 5166-5174.

[182] V. Ovchinnikov, M. Karplus and E. Vanden-Eijnden, J. Chem. Phys., 2011, 134,.
[183] I. Fdez. Galvn, A. Volbeda, J. C. Fontecilla-Camps and M. J. Field, Proteins, 2008, 73, 195-203.

[184] P.-h. Wang, R. B. Best and J. Blumberger, J. Am. Chem. Soc., 2011, 133, 3548-3556.

[185] P.-H. Wang, D. D. Sancho, R. Best and J. Blumberger, in Computational Approaches for Studying Enzyme Mechanism Part B, ed. G. A. Voth, Academic Press, 2016, vol. 578, pp. $299-326$. 